\title{
Autologous Adipose-Derived Stromal Cells and PRF Extract for Spontaneous Intervertebral Disc Disease in Canine
}

\author{
Sheng Chuan Lin ${ }^{1}$, I Wan Wang ${ }^{2}$, Tzong Fu Kuo ${ }^{3 *}$, Yan Der Hsuuw ${ }^{4}$, Shinn Chih Wu ${ }^{5}$ and Ko Tung Chang \\ ${ }^{1}$ Department of Tropical Agriculture and International Cooperation, National Pingtung University of Science and Technology, Taiwan \\ ${ }^{2}$ Deng Chuan veterinary hospital, Taiwan \\ ${ }^{3}$ Department of Post Baccalaureate Veterinary Medicine, Asia University, Taiwan \\ ${ }^{4}$ Department of Biological Science and Technology, Taiwan \\ ${ }^{5}$ Department of Animal Science and Technology, Taiwan
}

*Corresponding author: Ko Tung Chang, Department of Biological Science and Technology, NPUST, 91201, No.1, Sheufu Road, Neipu, Pingtung, Taiwan Tzong Fu Kuo, Department of Post Baccalaureate Veterinary Medicine, 500, Lioufeng Rd, Wufeng, Taichung 41354, Taiwan

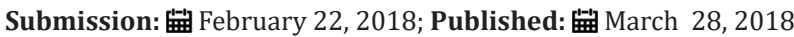

\begin{abstract}
The administration of autologous adipose-derived stromal cells (ADSC) and platelet-rich fibrin (PRF) extract by intra-venous injections was investigated as a treatment for canine intervertebral disc disease (IVDD). IVDD is a disease that can cause several symptoms in domestic dogs, ranging from pain to partial or complete paralysis. Five dogs suffered from IVDD that caused hind-legs paralysis with deep pain perception, were treated with autologous adipose-derived stromal cells, vascular fraction, and PRF extract. ADSC were expected to ameliorate symptoms of IVDD due to its antiinflammatory and cell regenerative action. Five sequential intravenous injections applied in one-week interval for five weeks improved condition of treated dogs judged by patients gait score and exercise pattern.
\end{abstract}

Keywords: Intervertebral disc disease; Adipose stromal stem cells; Platelet-rich fibrin; Stromal vascular fraction

Abbreviations: ADSC: Adipose Derived Stromal Cells; PRF: Platelet Rich Fibrin; IVDD: Intervertebral Disc Disease; MRI: Magnetic Resonance Imaging; CT: Computed Tomography; TGF- $\beta$ : Transforming Growth Factor; VEGF: Vascular Endothelial Growth Factor; EGF: Epidermal Growth Factor; PDGF: Platelet Derivative Growth Factor

\section{Introduction}

Intervertebral disc disease (IVDD) is a condition when the spinal intervertebral disc either bulged or herniated into the spinal cord space. IVDD can present with number of symptoms in domestic animals, ranging from a mild pain to partial or complete paralysis with preserved or lost deep pain perception. The symptoms of IVDD can be induced by acutely ruptured discs from an acute trauma or from other causes of disc herniation. IVDD occurs more commonly in some specific dog breeds, including the Dachshund, Beagle, Basset Hound, Poodle and Shih Tzu, but can occur in any breed and in dogs of any age or gender. There are three Hansen types of IVDD. In the Hansen type I, intervertebral discs become fragile due to calcification of their outer layer. Any forceful impact such as post-jumping can cause one or more discs to burst and the inner material can herniate and compress the spinal cord. Type 1 IVDD commonly affects the neck spine region in smaller dog breeds. With the Hansen type II herniation, discs become fibrous and harder over a long period of time and eventually break down, bulge out, and compress the spinal cord. Type III Hansen is a subtype of Hansen type I that the intervertebral disk degeneration and herniation characterized by extension of disk material "like a carpet over several vertebrae" [1].

A complete neurologic examination may suggest the location of the spine cord compression that can be specified by X-ray and in some cases by MRI (magnetic resonance imaging) or CT (computed tomography) examination. The path physiology of IVDD involves not only the initial mechanical damage, but also the secondary cascades of inflammation, ischemia free-radical formation, and cytotoxicity resulting in neuron death by necrosis or apoptosis. Regenerative medicine therapies based on biomaterials and stem cells application have been tested with promising results [2]. This clinical study reports the results of application of autologous adipose-derived stromal cells and platelet-rich fibrin (PRF) extract to dogs suffering from IVDD (Figure 1). 

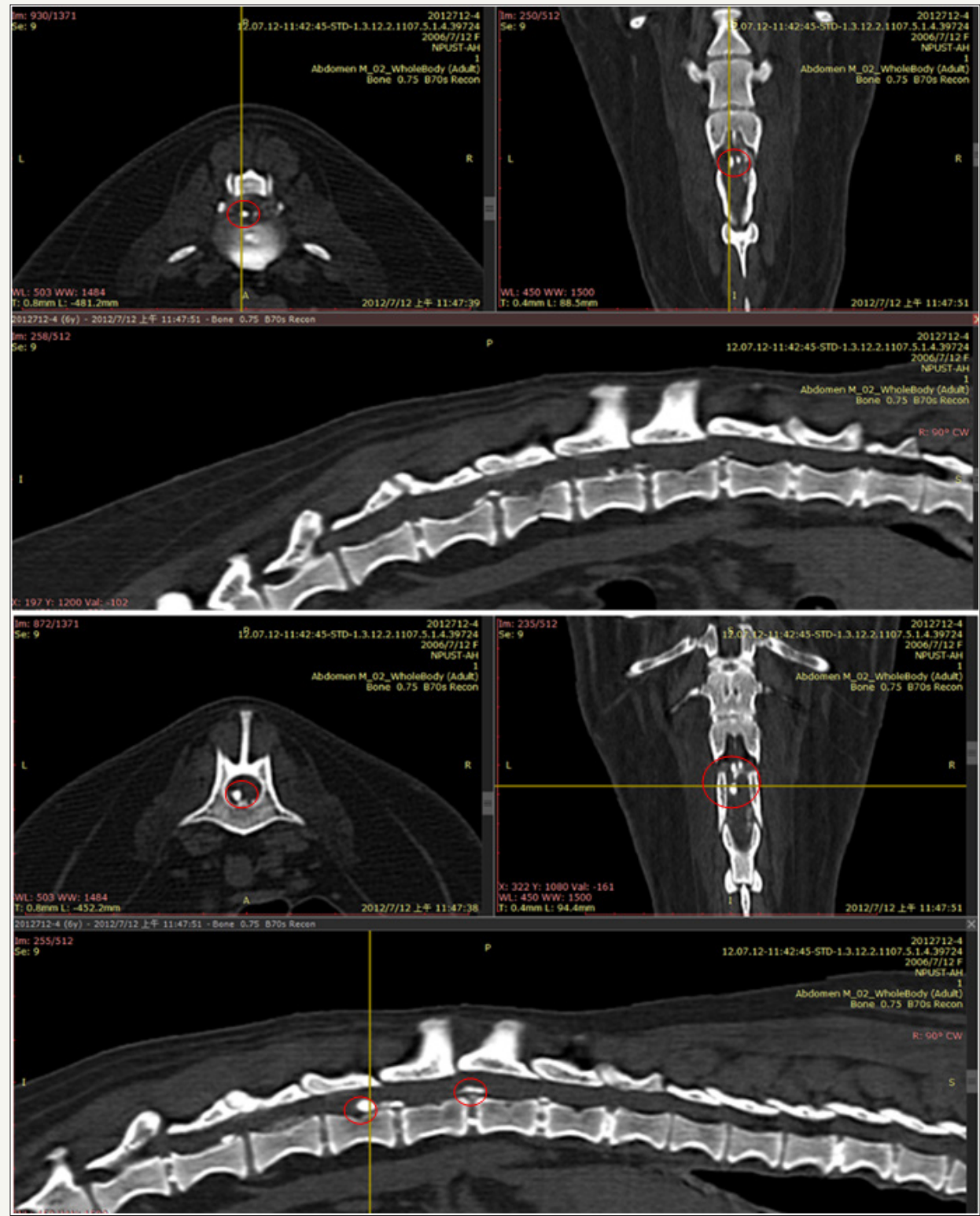

Figure 1 : Dog was diagnosed IVDD by CT examination. The dog exhibited complete paralysis and loss of the deep pain perception. IVDD locations are indicated by red-marked circles.

\section{Case Presentation}

In this study, all dogs with IVDD have symptoms that are confirmed by the $\mathrm{CT}$ scan and neurological examination as a spinal cord function disturbance (Table 1). All dogs lost the panicculi, urinary bladder continence, proprio reflex and deep pain perception (Table 2). They could not support their own body weight. The IVDD scale used for quantifying spinal cord abnormalities in these individuals indicated presence of the IVDD grade 5 . The five dogs that completed the experimental treatment program with ADSC and platelet-rich fibrin (PRF) extract exhibited an excellent gait performance. The paralysis ameliorated in four dogs and they could walk easily and with a good gait pattern after eight weeks (Table 3). The dog 1 did not improve well in eight weeks, but it showed good panicculi, urinary bladder continence and proprio reflex. The dog walked after 16 weeks after ADSC and platelet-rich fibrin (PRF) extract administration.

Table 1: Dogs with IVDD have symptoms that are identified by CT examinations.

\begin{tabular}{|c|c|c|c|c|c|}
\hline \multirow{2}{*}{ Examination Finding } & $\operatorname{Dog} 1$ & $\operatorname{Dog} 2$ & Dog 3 & Dog 4 & Dog 5 \\
\hline & (Yang-Mei) & (Pi-Dan) & (Ji-Li) & (Don-Don) & (Shau-Hai) \\
\hline CT scan Lesion & $\begin{array}{c}\text { T3-T4 } \\
\text { L1-2-3-4 }\end{array}$ & L1-L2 & $\begin{array}{c}\text { C4-C5 } \\
\text { T12-T13 }\end{array}$ & $\begin{array}{l}\text { T5-T6 } \\
\text { L1-L2 }\end{array}$ & T13-L1 \\
\hline
\end{tabular}




\begin{tabular}{|c|c|c|c|c|c|}
\hline X-ray exam & NSF & NSF & NSF & NSF & NSF \\
\hline Blood exam & Normal & Normal & Normal & Normal & Normal \\
\hline Biochemistry exam & Normal & Normal & Normal & $(-)$ & $(-)$ \\
\hline $\begin{array}{c}\text { SNAP 4DX Plus test } \\
\text { kit [22] }\end{array}$ & $(-)$ & $(-)$ & $(-)$ & \\
\hline
\end{tabular}

NSF: no specific finding.

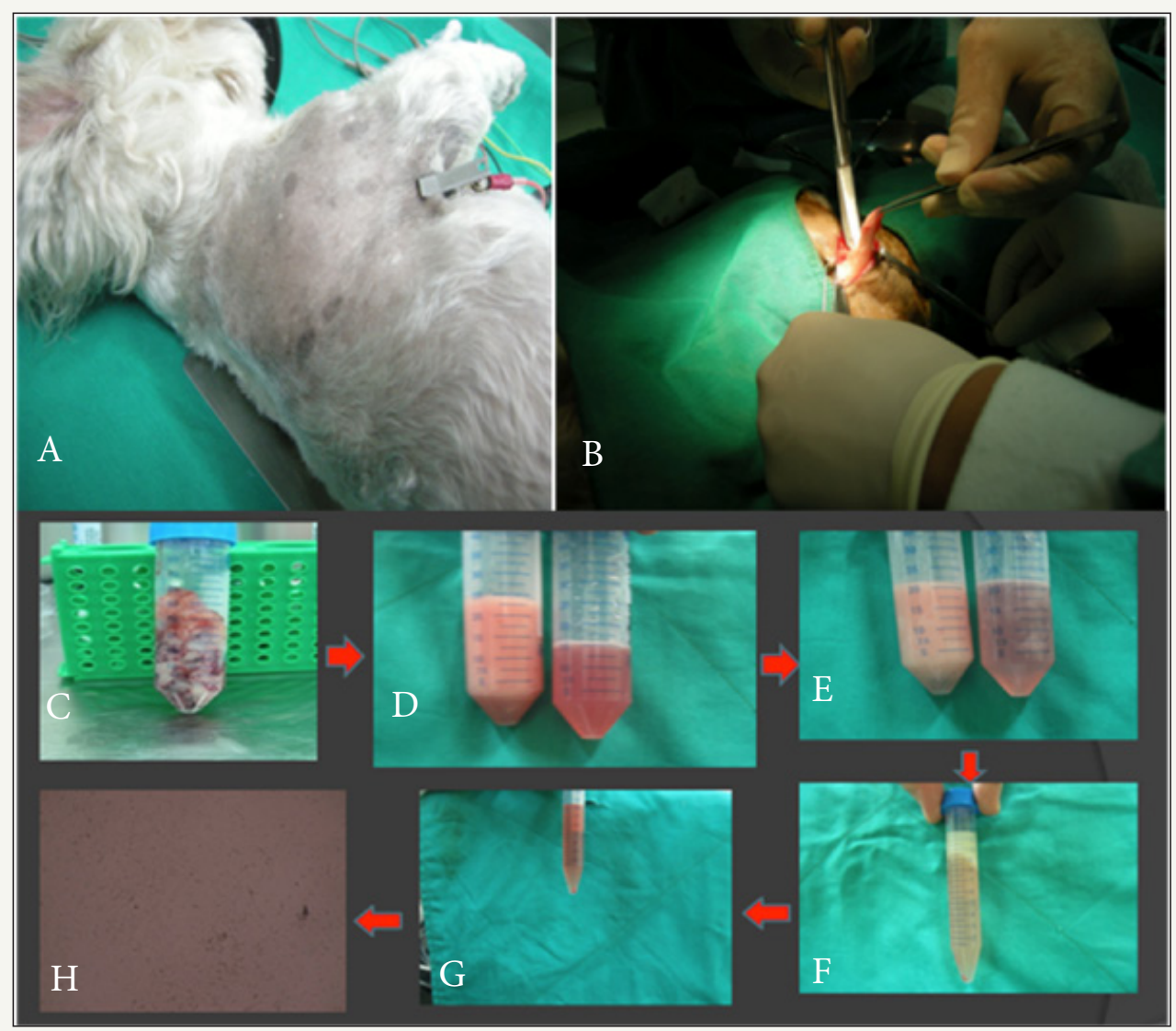

Figure 2 : The procedure for ADSC isolation and purification: Fat tissue was collected under general anaesthesia (A, B). Tissue samples were kept at $4-7^{\circ} \mathrm{C}$ and were washed three times with sterile saline to remove contaminating blood cells and tissue debris (D). The washed tissues were digested with an equal volume of $0.1 \%$ collagenase at $37^{\circ} \mathrm{C}$ for $30 \mathrm{~min}(\mathrm{E})$. The digested tissues then were inactivated with $10 \%$ fetal bovine serum (FBS) (F). The tissues were washed five times with saline and centrifuged at $300 \mathrm{~g}$ for $5 \mathrm{~min}$. The pallet was collected and resuspended (G). Cells in the pallet was observed under microscope (H) [21].

Table 2: Clinical findings of submitted dogs before stem cells therapy.

\begin{tabular}{|c|c|c|c|c|c|}
\hline \multirow{2}{*}{ Clinical Finding } & Dog 1 & $\operatorname{Dog} 2$ & Dog 3 & $\operatorname{Dog} 4$ & Dog 5 \\
\hline & (Yang-mei) & (Pi-dan) & (Ji-li) & (Don-don) & (Shau-hai) \\
\hline Panicculi reflex & $(-)$ & $(-)$ & $(-)$ & $(-)$ & $(-)$ \\
\hline Urinary Bladder continence & $(-)$ & $(-)$ & $(-)$ & $(-)$ & $(-)$ \\
\hline Proprio. reflex & $(-)$ & $(-)$ & $(-)$ & $(-)$ & $(-)$ \\
\hline Weight bearing & $(-)$ & $(-)$ & $(-)$ & $(-)$ & $(-)$ \\
\hline Deep pain perceptio & $(-)$ & $(-)$ & $(-)$ & $(-)$ & $(-)$ \\
\hline IVDD Grade & $(\mathrm{V})$ & (V) & (V) & (V) & $(\mathrm{V})$ \\
\hline Age & $8 y / 0$ & $4 y / o$ & $5 y / 0$ & $9 y / 0$ & $11 \mathrm{y} / \mathrm{o}$ \\
\hline Breed & Dachshund & Poodle & Dachshund & Dachshund & Mixed \\
\hline
\end{tabular}


Table 3: Clinical improvement of submitted dogs after stem cells therapy.

\begin{tabular}{|c|c|c|c|c|c|c|c|c|c|c|}
\hline \multirow{3}{*}{$\begin{array}{c}\text { Improve } \\
\text { time }\end{array}$} & \multirow{2}{*}{\multicolumn{2}{|c|}{$\begin{array}{c}\text { Dog } 1 \\
\text { (Yang-mei) } \\
\end{array}$}} & \multirow{2}{*}{\multicolumn{2}{|c|}{$\begin{array}{c}\text { Dog } 2 \\
\text { (Pi-dan) }\end{array}$}} & \multirow{2}{*}{\multicolumn{2}{|c|}{$\begin{array}{l}\text { Dog } 3 \\
\text { (Ji-li) }\end{array}$}} & \multirow{2}{*}{\multicolumn{2}{|c|}{$\begin{array}{c}\text { Dog } 4 \\
\text { (Don-don) }\end{array}$}} & \multirow{2}{*}{\multicolumn{2}{|c|}{$\begin{array}{c}\text { Dog } 5 \\
\text { (Shau-hai) }\end{array}$}} \\
\hline & & & & & & & & & & \\
\hline & 4wks & 8wks & 4wks & $8 w k s$ & 4wks & 8wks & $4 \mathrm{wks}$ & $8 \mathrm{wks}$ & $4 \mathrm{wks}$ & $8 \mathrm{wks}$ \\
\hline $\begin{array}{l}\text { Panicculi } \\
\text { reflex }\end{array}$ & $(-)$ & $(+)$ & $(+)$ & $(+)$ & $(+)$ & $(+)$ & $(+)$ & $(+)$ & $(+)$ & $(+)$ \\
\hline $\begin{array}{c}\text { Urinary } \\
\text { Bladder } \\
\text { continence }\end{array}$ & $(-)$ & $(+)$ & $(+)$ & $(+)$ & $(+)$ & $(+)$ & $(+)$ & $(+)$ & $(+)$ & $(+)$ \\
\hline $\begin{array}{c}\text { Proprio. } \\
\text { reflex }\end{array}$ & $(-)$ & $(+)$ & $(+)$ & $(+)$ & $(-)$ & $(+)$ & $(+)$ & $(+)$ & $(+)$ & $(+)$ \\
\hline $\begin{array}{l}\text { Weight } \\
\text { bearing }\end{array}$ & $(-)$ & $(-)$ & $(+)$ & $(+)$ & $(-)$ & $(+)$ & $(+)$ & $(+)$ & $(+)$ & $(+)$ \\
\hline Walk & $(-)$ & $(-)$ & $(+)$ & $(+)$ & $(-)$ & $(+)$ & $(+)$ & $(+)$ & $(+)$ & $(+)$ \\
\hline
\end{tabular}

\section{Discussion}

ADSC is from the adipose stromal vascular fraction (SVF) (Figure 2), which is comprised of the mononuclear cells derived from adipose tissue. This term is used to describe the mitotically active source of adipocyte precursors. SVF as a source of stem cells was first described by De Ugate et al. [3], who identified MSC-like cells in SVF that could be induced to differentiate into adipogenic, chondrogenic, myogenic, and oestrogenic lineages [3]. Subsequent to the initial description, the same group reported after in vitro expansion, the SVF derived cells had surface marker expression similar to bone marrow derived MSC, comprising CD29, CD44, CD71, CD90, CD105/SH2, and SH3 and lacking CD31, CD34, and CD45 expression.

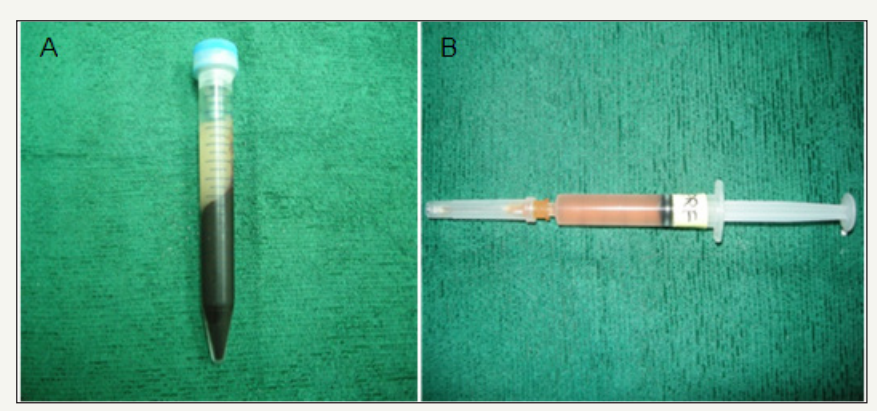

Figure 3 : Autologous platelet rich fibrin (PRF) extract was isolated from the dog's blood as described in materials and methods based on the paper [8].

(A) The PRF clots were retrieved from the tubes and the red blood cell gel was detached and discarded. Four PRF clots were transferred into sterile tubes. The tubes were put on a shaker and agitated gently. After 5 minutes, the tubes were vortexed to form a PRF membrane, and the volume of releasate was measured and returned into the tube. The tubes were further agitated gently.

(B)The extract was mixed with ADSC and injected by intravenously.

Autologous platelet-rich fibrin is prepared from patient blood (Figure 3). Platelet-rich fibrin is a new generation platelet derivative product. Fibrinogen is the final substrate of all coagulation reactions. Fibrinogen is a soluble protein and is transformed into an insoluble fibrin by thrombin while the polymerized fibrin gel constitutes the basic matrix of the injured site [4]. Platelet-rich fibrin is a specifically developed biomaterial for use in oral, maxillofacial surgery and tissue healing [5]. Fibrin adhesives are already used in cardiothoracic and vascular surgery. These adhesives are successfully used for the sealing of diffuse micro vascular bleeding through spray application [6]. Platelet-rich fibrin is collected from non-anticoagulant blood by centrifugation and the preparation of PRF is simple and can be accomplished during one procedure [7]. Platelet-rich fibrin contains several growth factors mainly including platelet derivative growth factor (PDGF)-AB, transforming growth factor beta (TGF- $\beta$ ), vascular endothelial growth factor (VEGF) and epidermal growth factor (EGF) [8]. Platelet growth factors have exhibited chemotactic and mitogenic properties [9] that promote and modulate cellular functions involved in tissue healing, cell regeneration and cell proliferation [10]. PRF contains not only a number of GFs, but also cytokines and inflammatory mediators [10]. Platelet derivative growth factor (PDGF-AB), tumour transforming growth factor (TGF- $\beta$ ), VEGF and EGF were expected to exhibit chemotactic and mitogenic properties that promote and modulate for IVDD clinic symptom relief, apoptosis inhibition and tissue healing.

In this study, we showed that the administration of ADSC and PRF extract could improve the damage of spinal cord in the intervertebral disc disease (IVDD) in dogs. The severity of IVDD was classified into five grades according to clinical signs and symptoms. Grade 1 includes spinal hyperesthesia, Grade 2 for ambulatory paraparesis, ataxia, proprioceptive deficits, Grade 3 for nonambulatory paraparesis, Grade 4 for paraplegia with nociception preserved, and Grade 5 for paraplegia with loss of nociception [11].

The stem cells application has demonstrated the promising result in spinal cord injury [12]. Several reports demonstrated effectiveness of bone marrow stromal cells implantation in acute spinal cord injury models, including monkey [13], human [14] and dogs $[15,16]$. In our study, the five dogs suffering from IVDD Grade $\mathrm{V}$ and experimentally treated with autologous cells derived from adipose tissue and PRF extract significantly improved their clinical 
condition.

According to Dr. Kim's research, the full recovery time in decompression surgery for IVDD was about 62.25 days. The decompression surgery plus ADSC local graft was 59.7days for recovery to grade 1 [17]. In this study, we combined ADSC and PRF extract to treat grade 5 IVDD patients. The average recovery time was about 48 days. It thus appears as a better recovery than that from decompression surgery.

The spinal cord undergoes inflammation response by primary hurt $[18,19]$. The reddish, swelling, heat, hemorrhage and function loss were induced in damaged area. Another physic or mechanical procedures could induce more cell death and hemorrhage. The more serious injuries were induced to form the glia scar in spinal cord [20-22]. ADSC and PRF extract were supposed to decrease the inflammation cytokines such as IL 6 and TNF- $\alpha$ and limited the inflammation cascade pathway $[23,24]$.

This study, though limited in size, successfully tested a novel treatment procedure for dogs suffering from IVDD in canine. The performance of the clinical dog patients in this preliminary study encourages us to go toward a brilliant direction.

\section{Consent of Patients}

The experimental protocol was approved by the Deng Chuan veterinary hospital, Kaohsiung, Taiwan and all participants provided informed consent before the study.

\section{Acknowledgement}

This study was partly supported by the Ministry of Science and Technology in Taiwan (grant MOST 106-2314-B-020-001 and MOST 104-2314-B-020-001-MY3). The authors thank to Ms. Shin-Peir Aui, who works at BST115, NPUST, for her assistance in proofreading.

\section{Conflict of Interest Statement}

The authors have declared no conflict of interest.

\section{References}

1. De Risio L (2015) A review of fibro cartilaginous embolic myelopathy and different types of per acute non-compressive intervertebral disk extrusions in dogs and cats. Front Vet Sci 2: 24.

2. Kuroda R, Ishida K, Matsumoto T, Akisue T, Fujioka H, et al. (2007) Treatment of a full-thickness articular cartilage defect in the femoral condyle of an athlete with autologous bone-marrow stromal cells. Osteoarthritis Cartilage 15(2): 226-231.

3. De Ugarte DA, Alfonso Z, Zuk PA, Elbarbary A, Zhu M, et al. (2003) Differential expression of stem cell mobilization-associated molecules on multi-lineage cells from adipose tissue and bone marrow. Immunol Lett 89(2-3): 267-270.

4. Clark RA (2001) Fibrin and wound healing. Ann N Y Acad Sci 936: 355367.

5. Anilkumar K, Geetha A, Umasudhakar TR, Vijayalakshmi R, Pameela E (2009) Platelet-rich-fibrin: A novel root coverage approach. J Indian Soc Periodontol 13(1): 5054.

6. Dohan DM, Choukroun J, Diss A, DohanSL, Dohan AJ, et al. (2006)
Platelet-rich fibrin (PRF): A second-generation platelet concentrate. Part I: Technological concepts and evolution. Oral Surg Oral Med Oral Pathol Oral Radiol Endod 101(3): e37-e44.

7. Choukroun J, Diss A, Simonpieri A, Girard MO, Schoeffler C, et al. (2006) Platelet-rich fibrin (PRF): A second-generation platelet concentrate. Part V: Histologic evaluations of PRF effects on bone allograft maturation in sinus lift. Oral Surg Oral Med Oral Pathol Oral Radiol Endod 101(3): 299303.

8. Su CY, Kuo YP, Tseng YH, Su CH, Burnouf T (2009) In vitro release of growth factors from platelet-rich fibrin (PRF): a proposal to optimize the clinical applications of PRF. Oral Surg Oral Med Oral Pathol Oral Radiol Endod 108(1): 56-61.

9. Dohan DM, Choukroun J, Diss A, Dohan SL, Dohan AJ, et al. (2006) Platelet-rich fibrin (PRF): A second-generation platelet concentrate. Part III: Leucocyte activation: A new feature for platelet concentrates? Oral Surg Oral Med Oral Pathol Oral Radiol Endod 101(3): e51-e55.

10. Lucarelli E, Beretta R, Dozza B, Tazzari PL, O'Connel SM, et al. (2010) A recently developed bifacial platelet-rich fibrin matrix. Eur Cell Mater 20: $13-23$.

11. Penning V, Platt SR, Dennis R, Cappello R, Adams V (2006) Association of spinal cord compression seen on magnetic resonance imaging with clinical outcome in 67 dogs with thoracolumbar intervertebral disc extrusion. J Small Anim Pract 47(11): 644-655.

12. Antonic A, Sena ES, Lees JS, Wills TE, Skeers P, et al. (2013) Stem cell transplantation in traumatic spinal cord injury: a systematic review and meta-analysis of animal studies. PLoS Biol 11(12): e1001738.

13. Deng YB, Yuan QT, Liu XG, Liu XL, Liu Y, et al. (2005) Functional recovery after rhesus monkey spinal cord injury by transplantation of bone marrow mesenchymal-stem cell-derived neurons. Chin Med J 118(18): 1533-1541.

14. Pal R, Venkataramana NK, Bansal A, Balaraju S, Jan M, et al. (2009) Ex vivo-expanded autologous bone marrow-derived mesenchymal stromal cells in human spinal cord injury/paraplegia: a pilot clinical study. Cytotherapy 11(7): 897-911.

15. Jung DI, Ha J, Kang BT, Kim JW, Quan FS, Lee JH, et al. (2009) A comparison of autologous and allogenic bone marrow-derived mesenchymal stem cell transplantation in canine spinal cord injury. J Neurol Sci 285(1-2): 67-77.

16. Nishida H, Nakayama M, Tanaka H, Kitamura M, Hatoya S, et al. (2011) Evaluation of transplantation of autologous bone marrow stromal cells into the cerebrospinal fluid for treatment of chronic spinal cord injury in dogs. Am J Vet Res 72(8): 1118-1123.

17. Kim Y, Lee SH, Kim WH, Kweon OK (2016) Transplantation of adipose derived mesenchymal stem cells for acute thoracolumbar disc disease with no deep pain perception in dogs. J Vet Sci 17(1): 123-126.

18. Nandoe Tewarie RD, Hurtado A, Levi A, Grotenhuis JA (2006) Bone marrow stromal cells for repair of the spinal cord: towards clinical application. Cell Transplant 15(7): 563-577.

19. Young W (1993) Secondary injury mechanisms in acute spinal cord injury. J Emerg Med 1: 13-22.

20. Fitch MT, Silver J (2008) CNS injury, glial scars, and inflammation: inhibitory extracellular matrices and regeneration failure. Exp Neurol 209(2): 294-301.

21. Chang H, Do BR, Che JH, Kang BC, Kim JH, et al. (2013) Safety of adiposederived stem cells and collagenase in fat tissue preparation. Aesthet Plast Surg 37(4): 802-808.

22. Schnyder M, Deplazes P (2012) Cross-reactions of sera from dogs infected with Angiostrongylus vasorum in commercially available dirofilaria immitis test kits. Parasit Vectors 5: 258. 
23. Zhu L, Fan M, Zhang H (2017) Application of platelet rich fibrin combined with atorvastatin in the regeneration treatment of degree II furcation involvements of mandibular molars. Biomed Res 28: 22.
24. Li X, Lu X, Sun D, Wang X, Yang L, et al. (2016) Adipose-derived mesenchymal stem cells reduce lymphocytic infiltration in a rabbit model of induced autoimmune dacryoadenitis. Invest Ophthalmol Vis Sci 57(13): 5161-5170 (c) (i) Creative Commons Attribution 4.0

For possible submissions Click Here
Submit Article

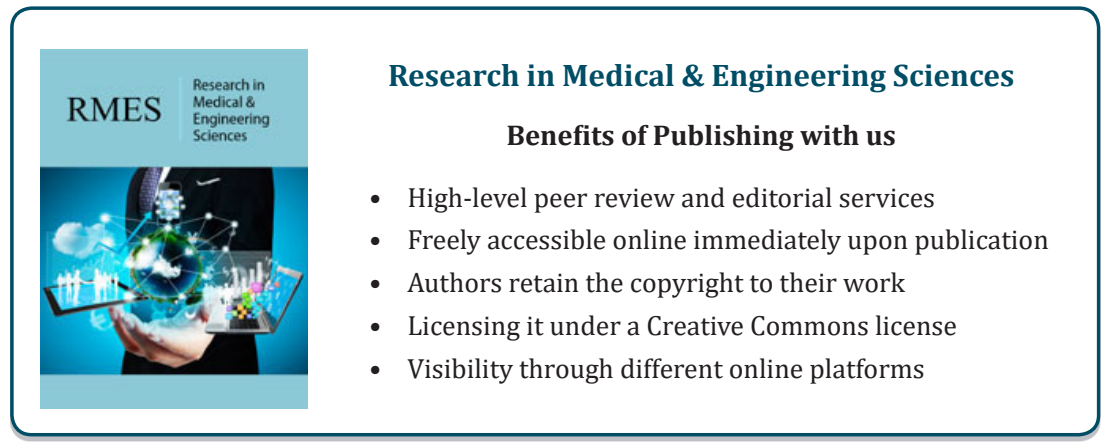

